\title{
Yaşlı kalça kırı̆ı̆ önlenmesi için yaşam dizaynı; ev, iş ve sosyal hayatta düzenlemeler
}

\section{The lifestyle design for the prevention of hip fracture in elderly; regulations in house, work and social life}

\author{
Sevgi Atar, Ömer Kuru
}

SBÜ Prof. Dr. Cemil Taşçıoğlu Şehir Hastanesi, Fiziksel Tıp ve Rehabilitasyon Kliniği, İstanbul

\begin{abstract}
Kalça kırıkları yaşlılarda ölümle sonuçlanabilecek önemli bir sağlık sorunudur. Tedavisinde cerrahi müdahale, uzun hastane kalış süresi ve uzun rehabilitasyon programı gerektirir. Osteoporoz önemli bir risk faktörüdür. Tedavi başarısı ileri yaş, osteoporoz ve eşlik eden hastalıkların etkisiyle düşüktür. Bu nedenle kalça kırığının önlenmesine yönelik çok alanlı, önleyici profesyonel yaklaşımın önemi büyüktür. Yürüyüş ve denge egzersizleri ile hastalar desteklenmelidir. Kemik yoğunluğuna destek amacı ile D vitamini ve kalsiyum destek tedavisi düzenlenmelidir. Kişilerin görme kaybını düzeltecek tedavi seçenekleri değerlendirilmelidir. Ev ortamında düşme ihtimalini artıran işlerin ne şekilde yapılacağı düzenlenmeli; aydınlatma, tutunma barı ve kaymayı önleyici kaplamalar hakkında bilgi verilmelidir. Aktif ve kontrollü bir yaşam tarzı planlanmalıdır. Doğa yürüyüşleri, dans ve yüzme gibi aktivitelerle hem yaşlıların vaktini kapalı ev ortamında geçirmelerinin önüne geçilmeli hem de kas kuvvetleri desteklenmelidir. İş hayatında uzun süreli oturma, ani ayağa kalkma ve yükseğe uzanma gibi riskli işlemlerden sakınılmalıdır.
\end{abstract}

Anahtar sözcülkler: kalça kırığı; yaşlılık; osteoporoz; önlem
Hip fracture is an important health problem that can result in death in the elderly. It requires surgical intervention, long hospital stay and a long rehabilitation program for the treatment. Osteoporosis is an important risk factor. Treatment success is low due to advanced age, osteoporosis and patients' other comorbidities. Therefore, a multidisciplinary preventive professional approach is of great importance in preventing hip fracture. Patients should be supported with walking and balance exercises. Vitamin D and calcium supplement therapy should be arranged to support bone density. Treatment options that will correct patients' vision loss should be evaluated. How to do the works that increase the possibility of falling at home environment should be rearranged, and it is important to give information about lighting, grab bar, anti-slip coatings. An active and controlled lifestyle should be planned. The elderly should be prevented from spending their time in a closed home environment with the help of the activities such as hiking, dancing, swimming and in this way their muscle strength should be supported. Risky procedures such as prolonged sitting, sudden standing up and reaching up in work life should be avoided.

Key words: hip fracture; elderly; osteoporosis; prevention
K alça kemiklerinin kırığı yaşlılarda sık görülür. Yaşlılarda düşmenin ciddi sonuçlarından biridir. Yaşlılarda görmenin azalması ile denge kaybının artması ve osteoporoz gelişmesi kalça kırığı görülmesindeki en önemli etkenlerdir. ${ }^{[1,2]} 2000$ 'lerin başında Amerika Birleşik Devletleri (ABD)'nde yılda 250.000 olgu görülürken, 2018 yılında bu rakam iki katına çıkmıştır. ${ }^{[3,4]}$ Yine ABD'de kalça kırıklarının 2010 yılında tedavi giderlerinin 17 ila 20 milyar dolar arasında olduğu bildirilmiştir. ${ }^{[5]}$ Yüz düşme olgusunun birinde kalça kırığı görülür ancak bu olguların büyük bir kısmında kalıcı sakatıı, maliyeti yüksek tedavi süreci ve hatta ölümle sonuçlanan bir tablo da görülebilmektedir. Bu olguların büyük bir kısmı 65 yaş ve üzeridir. Önümüzdeki 10 yılda da olgu sayısının ikiye katlanması beklenmektedir. ${ }^{[3,5]}$ Artış görülmesinin önemli bir sebebi popülasyonda yaşlı nüfusun artışıdır. Kalça kırıklarının \%95'den fazla nedeni düşmelerdir. Düşme olaylarının büyük bir kısmı yan tarafına düşme şeklinde gerçekleşir. ${ }^{[5,6]}$

- Illetişim adresi: Uzm. Dr. Sevgi Atar, SBÜ Prof. Dr. Cemil Taşçıŏglu Şehir Hastanesi, Fiziksel Tıp ve Rehabilitasyon Kliniği, Darülaceze Caddesi No:27 Okmeydanı, Şişli, İstanbul Tel: 0505 - 2123296 E-posta: sevgiatar@gmail.com 
Kalça kırıkları genellikle büyük cerrahi müdahaleler gerektirir ve hasta iletişimi oldukça güçtür. Kadınlarda erkeklere göre yaklaşık 3 kat daha fazla görülür çünkü kadınlarda osteoporoz görülme sıklığı erkeklere göre daha fazladır. ${ }^{[4,7]}$ Kırıkların yaklaşık \%45-50'si kapsül içidir, femur baş ve boynunu kapsar. İkinci sırada \%40-45 oranlarda intertrokanterik kırıklar görülür. íkisinin birlikte görüldügü kırıklar \%5-10’luk oranlarda görülür. Bu travmalar genellikle düşme gibi düşük enerjili travmalardır. Trafik kazaları gibi yüksek enerjili travmaya bağlı kalça kırıkları daha genç yaşlarda görülür. ${ }^{[5,8]}$

Illeri yaş hastalar hekim tarafından periyodik olarak muayene edilmeli ve kalça kırıkları konusunda hasta bilinçlendirilmelidir. Denge ve görme üzerinde yan etkisi fazla olan ilaçlar hekim tarafından değiştirilmeli, yeterli D vitamini ve kalsiyum destek tedavisi sağlanmalıdır. Osteoporozun takibi, güç ve denge egzersizlerinin planlanması, göz muayenelerinin tamamlanması ve ev içinde güvenlik amacı ile yapılacak düzenlemelerin önerilmesi hekimlerin kalça kırıklarının önlenmesinde uygulayabilecekleri yaklaşımlardır. ${ }^{[3,9,10]}$

\section{KAS GÜÇLENDIRME VE DENGE EĞiTiMi}

Yapılan çalışmalarda vücut kitlesi, vücut ağırlı̆̆ının artmasıyla birlikte yan tarafa düşmelerde kalça kırığı oluşma ihtimali artmaktadır. Orta derecede egzersiz önerileri kas kuvvetini artırıp kemik yoğunluk kaybını azaltabilir. Güçlendirme ve eğitim programları çok alanlı bir yaklaşım gerektirir. Yaşlılarda kronik hastalıkların varlığı göz önünde bulundurulmalı, diyabet, hipertansiyon, kronik obstrüktif akciğer hastalıkları, osteoporoz, obezite, görme ve işitme kaybı teşhis ve tedavisi düşme ihtimalini azaltmada yardımcı olacaktır. ${ }^{[11,12]}$

\section{OSTEOPOROZ TANI VE TEDAVISi}

Genetik yatkınlık kemik döngüsü üzerinde etkilidir ve hem yaşla birlikte hem de tek başına menopoz dönemi bu döngü üzerinde hızlandırıcı bir zemin hazırlar. Genetik faktörler kişide osteoporoz oluşmasında etkili olsa da diyet ve yaşam düzenlemesi ile bu etkinin önüne geçilebilir. İnsanlara küçük yaşlardan itibaren süt tüketiminin teşvik edilmesi, menopoz sonrası östrojen destek tedavisi düzenlenmesi ve yaşlılığa ikincil hiperparatiroidizm tedavisi önemlidir. Kemik yoğunluk ölçümü osteoporoz tanı ve takibinde kullanılır. Kalça kırığı oluşmasında kemik yoğunluğunun azalması önemli bir zemin hazırlayıcı faktördür. Bu nedenle yaşlı popülasyonda kemik yoğunluğu ölçümleri araştırılarak osteoporoz varlığında gerekli destek tedavisi verilmelidir. Güneşli mevsimlerde yaşlıların açık havada günde 20-30 dakika kadar güneş ışını alması D vitamini sentezi için önerilebilir. ${ }^{[13,14]}$

\section{DIYET DÜZENLEMESi}

Süt ürünleri başlıca kalsiyum kaynağıdır. Günlük süt ve süt ürünlerinin düzenli tüketimi sağlanmalıdır. Kalsiyumdan zengin diğer besinler, lahana, brokoli, fındık, fistık, badem ve koyu yeşil sebzelerdir. Günlük olarak taze sebze ve meyve tüketen kadın ve erkeklerde kalça kırık riskinin daha az tüketenlere göre daha az olduğu bildirilmektedir. ${ }^{[15]} \mathrm{D}$ vitamini, güneş ışınlarında bulunan ultraviyole ışınlara maruziyet yoluyla vücutta sentezlenebilir ya da eksojen olarak dışarıdan alınabilir. D vitamini, kalsiyumun emilimini ve kemik yoğunluğunu artırır. Böylece kalça kırı̆̆ı oluşma riskini azaltır. Yaşlı popülasyon az hareket ettiği ve kapalı ortamlarda daha fazla vakit geçirdiğinden güneş ışınlarına daha az maruz kalır. Bu nedenle vücutlarının $D$ vitamini sentezi azaldığından kalsiyum emilimi de azalır. Bu eksikliğin giderilmesi için diyet ile birlikte D vitamini (günlük $800 \mathrm{IU}$ ) ve kalsiyum (günlük 1200 miligram) içeren preparatların takviye amacı ile hekim kontrolünde verilmesi yararlı olabilir. ${ }^{[9,14]}$ Soda tüketiminin içerdiği fosforik asit nedeni ile azaltılması önerilmektedir. ${ }^{[16]}$ Aşırı alkol tüketiminden uzak durulmalı, sigara alışkanlığının önüne geçilmelidir. Tütün ve alkol tüketimi kemik yoğunluğunda azalmaya yol açmaktadır. Ayrıca kahve içerisinde yer alan kafeinin düşük kemik yoğunluğuna neden olduğu bildirilmektedir. ${ }^{9,14,17,18]}$

\section{AKTIF YAŞAM TARZI PLANLAMASI VE EGZERSIZ}

Sigara ve alkol tüketimi artarken ve günlük hareketli aktivitelerin kısıtlanması kemiklerde güçsüzlüğe yol açar. Yaşla birlikte artan ilaç kullanımına bağlı yan etkiler oluşabilir. Uyuşukluk ve baş dönmesi düşmeye neden olabilecek istenmeyen yan etkilerdendir. Fiziksel düşkünlük, görme azalması, dengesizlik, demans ve benzeri tablolar ev içerisinde düşme ihtimalini artırabilmektedir. ${ }^{[19]}$

Günümüz iş hayatı sürekli oturma pozisyonunda iken sürdürülmektedir, aynı şekilde emeklilikte de evde sürekli oturmak kas-iskelet sistemini zayıflatacaktır. Bu nedenle gündüz vaktini oturarak geçirmekten uzak durulmalıdır. Kesintisiz oturmaya devam edilmemeli, belli aralıklarla kalkılıp yürüyüş yapılmalıdır. Gün içerisinde 30-60 dakika sürecek egzersiz ya da yürüyüş programı aktif yaşam tarzı için atılmış büyük bir adımdır. Yakındaki bir fırın ya da market alışverişine araba ile gitmek yerine yürüyüş yapılması, 
hareket imkânı çok olan (yoga grupları, dans kursları vb.) aktivitelere katılım, merdiven çıkma, yüzme, park ve doğa yürüyüşleri kişinin kendini çok zorlamadan yapabileceği etkinliklerdir. Orta şiddette egzersizlere devam edilmesi kemik kaybının hızını yavaşlatır ve kas gücünü artırır. Ayrıca denge ve koordinasyona da yardımcı olur. ${ }^{[1,2,4,19,20]}$

Obez hastalarda düşük kilolu hastalara göre düşme sonrası kalça kırığı riskinin az olduğu değerlendirilmiştir. ${ }^{[11,21]}$ Obez hastalarda kalça etrafındaki fazla yağ dokusunun yastıkçık görevi görmesiyle düşme sırasında kalçayı koruduğu ve kırık riskini azalttı̆̆ı öne sürülmekle birlikte, obeziteye bağlı ek hastalıklar da olası bir kalça kırığında cerrahi tedavi ve iyileşme sürecini zorlaştırabilir. ${ }^{[11,20,21]}$

\section{DÜŞME RISKININ AZALTILMASI}

İyi bir görme keskinliği düşme ve çarpma ihtimalini azaltacaktır. Kırklı yaşların ortasından itibaren prespiyopi kontrolleri yapılması önerilmektedir. Bu nedenle, ileri yaşlarda periyodik göz muayenesi yapılmalı, gözlük ve lens kontrolleri ihmal edilmemelidir. Yaşlı popülasyon kronik hastalıklar nedeni ile çok sayıda ilaç kullanabilmektedir. Bu ilaçlara bağlı uykusuzluk, dengesizlik ve sersemlik hali gelişebilir. Düşme riskini artıran bu gibi yan etkilerin giderilmesi için ilgili branş hekimlerine başvurulmalı ve yan etkileri az olan alternatifleri ile değiştirilmelidir. Yine yaş ya da psikolojik nedenlerle gelişen uykusuzluk durumlarında dikkat dağınıklığı, dengenin azalması gibi risk içeren durumlar yaşanabilir. Terapi ve medikal tedavi ile uykusuzluğun giderilmesine çalışılmalıdır. Yaşla birlikte artan işitme kaybı ve vestibüler sistem bozukluklarının tanı ve tedavisi için ilgili hekim değerlendirmelerinin yapılması düşme riskini azaltabilir. ${ }^{[2,4,20,21]}$

Yataktan ya da koltuktan uzun süreli oturduktan sonra aniden kalkılmamalıdır. Aniden ayağa kalkmak kan basıncını düşürebilir ve düşmeye neden olabilir. Özellikle kış aylarında dışarı çıkılması gerektiğinde yaya yollarında buzlanma ve kaygan zemin olup olmadığı kontrol edilmelidir. Mümkünse bu tür mevsim koşullarında dışarı çıkılmamalıdır. Taban yüzeyleri kaymaz özellikte ayakkabı giyilmesi, yürüyüş esnasında destek alarak ve düşük tempolu yürünmesi düşme riskini azaltabilir. Eğer yürümekte güçlük çekiliyor ve dengesizlik hissediliyor ise destek almak amacı ile hekim tavsiyesine göre walker (yürüteç), baston, kanedyen, tripod aletlerinden biri kullanılabilir. ${ }^{[4,22]}$

İş hayatında uzun süreli oturma, ani ayağa kalkma, dik merdivenlerden inme, görüş alanını kapatacak şekilde yük taşıma, düşük aydınlatmalı işlerde görev alma ve yükseğe uzanma gibi riskli işlemlerden sakınılmalıdır. Yürüyüş koridorlarında yerde elektrik kablolarının olmamasına özen gösterilmelidir. Geçiş yerlerinde eşik, yükselti ve üstü açık kalmış yer boşluklarının olmaması sağlanmalıdır. ${ }^{[2,20,23]}$

Ulaşım ya da spor amacı ile dışarıda bisiklet, motorsiklet ya da iki tekerlekli ulaşım araçlarını güvenlik tertibatsız kullanmak düşme ve kırık riskini artırabilir. Toplu ulaşım araçları durmadan kapı ve merdivenlerinden araçlara inme ve binme yapılmamalıdır. Ayakta desteksiz yolculuk yapmaktan sakınılmalıdır. Uzun süreli oturarak yapılacak yolculuklardan uzak durulması ve molalarda araç durduktan sonra kısa yürüyüşler yapılmalıdır. Havuz, kaplıca vb. su ile kayganlaşmış sert zemin barındıran ortamlarda güvenlik ikaz ve önlemlere dikkat edilmelidir. Aşırı sıcak ya da soğuk suyun kan basıncı üzerindeki ani etkileri olabileceğinden temastan uzak durulması önerilmelidir. ${ }^{[4,21-24]}$

\section{EVDE GÜVENLIĞiN SAĞLANMASI}

Kalça kırıklarının çoğu düşme sonucu oluşur. Düşme olgularının çoğu da ev ortamında gerçekleşir. Ev hayatında yapılacak güvenlik artırıcı düzenlemelerle pek çok düşme olayı önlenebilir. Ev içi aydınlatmanın yeterli düzeye getirilmesi ilk yapılacak işlemlerden birisidir. Yaşla birlikte görmenin azalması ve denge bozukluklarının artması nedeni ile karanlık ve loş ortamlar düşme ihtimalini artırabilir. Ev içinde eşyaların ve mobilyaların düzenli tutulması, dağınıklığın giderilmesi travma ihtimalinin azalmasına ve tökezleme riskinin önlenmesine yardımcı olacaktır. Banyo zemini kaymayı önleyici materyaller ile kaplanabilir ve tuvalet yakınına ve banyo içine tutunma barı konulabilir. ${ }^{[10,25]}$

Ev içinde merdiven bulunması önemli bir risk faktörüdür ve böyle durumlarda merdiven için de her iki tarafa da tutunma barı konulması önerilir. Yüksek raf kullanımının tercih edilmemesi, mobilyaların baş üstünden daha yüksek kısımlarında toz temizliği gibi eylemlerden sakınılması önerilmektedir. Bununla birlikte dolapların arka kısmının, devrilme ihtimali olan cisimlerin etrafının ve üst rafların tozlarının alınması olabildiğince uzak durulması gereken düşme riskini artıran işlemlerdir. Mobilyaların sivri kısımlarının yuvarlak koruyucularla kaplanması ya da değiştirilmesi de yaralanma ve düşme riskini azaltabilir. Koridorlarda hafif ve kaymaya müsait halı ve kilimlerin kaldırılması ya da bu eşyaların altının kaymaz özellikte kaplamalar ile kaplanması önerilebilir. ${ }^{[21-25]}$

Elektrikli ev aletlerinin uzun elektrik kabloları ev içerisinde yürüyüş alanlarından geçmemelidir. Kablolara bağlı takılıp düşme kalça kırığına neden 
olabilmektedir. Kabloların duvar kenarlarından geçirilmesi ya da otomatik sarımlı kablo makaraları kullanılabilir. Sandalye ya da yüksek basamak üzerine çıkıp ampul değiş̧irmek düşme için büyük risk oluşturur. Aydınlatma için abajur, yer lambası ya da duvardan aplik aydınlatma yapılması, tavan ampullerinin uzun ömürlü ve ev ortamında uygun şiddette aydınlatması olan ampullerin tercih edilmesi, ampul değişimi zaruri ise tek başına işlemin yapılmayıp yardım alınması düşme riskini azaltabilir. Işık düğmelerinin görünmesini kolaylaştırmak için üzerilerinde karanlıkta parlayan kağıtlar yapıştırılması karanlık ortamlarda takılıp düşme riskini azaltabilir. ${ }^{[10,19,20]}$

Ev içerisinde giyilen terliklerin sağlam materyalden yapılmış olması, ayağa tam oturması ve tabanlarının kaymaz özelliğe sahip olması önerilmektedir. Yürüyüş alanlarında zemin üzerinde küçük eşyaların, kırık parçaların ya da dökülmüş sıvıların olması kayma ve düşme ihtimalini artırabilir. Dağınıklığın önlenmesi, eşya ya da sıvıların yere dökülmesi sonrası kısa sürede temizlenmesi önemlidir. Hekimin yaşlı hastaların zihinsel ve bilişsel durumlarının evde tek başına yaşam için yeterli olup olmadığını değerlendirmesi ve buna göre önerilerde bulunması önemlidir. ${ }^{[2,3,25]}$

Özellikle osteoporoz saptanan ve denge kaybı olan kişilerde kalça koruyucu kullanımı önerilebilir. Kalça koruyucu kullanımının yaşlıların günlük kullanımda aksatması ve ihmal etmesi önemli bir kısıtlayıcı faktördür. ${ }^{[9,10,26]}$

\section{SONUÇ}

Kalça kırığına neden olabilecek risk faktörlerinin anlaşılması ve tespit edilerek önlem alınması önemlidir. Kas kuvveti ve kemik yoğunluğunu güçlendirecek terapi ve tedavi stratejilerinin iyi planlanması gerekmektedir. Hekim tarafından, yaşlıların ev ve sosyal ortamlarda alması gereken önlemlerin planlanması birey sağlı̆̆ına yönelik tıbbi destek tedavisi ile bir bütün olarak ele alınmalıdır.

\section{KAYNAKLAR}

1. Cooper C, Campion G, Melton LJ. Hip fractures in the elderly: a worldwide protection. Osteoporosis Int 1992;2(6):285-9. Crossref

2. Cummings $S R$, Rubin SM, Black $D$. The future of hip fractures in the United States. Clin Orthop 1990;(252):163-66. Crossref

3. Brauer CA, Coca-Perraillon $M$, Cutler DM, Rosen AB. Incidence and mortality of hip fractures in the United States. JAMA 2009;302(14):1573-9. Crossref

4. Stevens JA, Olson S. Reducing falls and resulting hip fractures among older women. MMWR Recomm Rep 2000;49(RR2):3-12. https://www.cdc.gov/mmwr/preview/mmwrhtml/ rr4902a2.htm
5. Miyamoto RG, Kaplan KM, Levine BR, Egol KA, Zuckerman JD. Surgical management of hip fractures: An evidence-based review of the literature. I. Femoral neck fractures. J Am Acad Orthop Surg 2008;16(10):596-607. Crossref

6. Hayes WC, Myers ER, Morris JN, Gerhart TN, Yett HS, Lipsitz LA. Impact near the hip dominates fracture risk in elderly nursing home residents who fall. Calcif Tissue Int 1993;52(3):192-8. Crossref

7. Parkkari J, Kannus P, Palvanen M, Natri A, Vainio J, Aho $\mathrm{H}$, Vuori I, Järvinen M. Majority of hip fractures occur as a result of a fall and impact on the greater trochanter of the femur: a prospective controlled hip fracture study with 206 consecutive patients. Calcif Tissue Int 1999;65(3):183-7. Crossref

8. Dillon MF, Collins D, Rice J, Murphy PG, Nicholson P, Mac Elwaine J. Preoperative characteristics identify patients with hip fractures at risk of transfusion. Clin Orthop Relat Res 2005;(439):201-6. Crossref

9. Chapuy MC, Arlot ME, Duboeuf F, Brun J, Crouzet B, Arnaud S, Delmas PD, Meunier PJ. Vitamin D3 and calcium to prevent hip fractures in elderly women. N Engl J Med 1992;327(23):1637-42. Crossref

10. Greenspan SL, Myers ER, Kiel DP, Parker RA, Hayes WC, Resnick NM. Fall direction, bone mineral density, and function: risk factors for hip fracture in frail nursing home elderly. Am J Med 1998;104(6):539-45. Crossref

11. Cummings SR, Nevitt MC, Browner WS, Stone K, Fox KM, Ensrud KE, Cauley J, Black D, Vogt TM. Risk factors for hip fracture in white women. Study of Osteoporotic Fractures Research Group. N Engl J Med 1995;332(12):767-73. Crossref

12. Ettinger B, Genant HK, Cann CE. Long-term estrogen therapy prevents bone loss and fracture. Ann Intern Med 1985;102(3):319-24. Crossref

13. Duboeuf F, Braillon P, Chapuy MC, Haond P, Hardouin C, Meary MF, Delmas PD, Meunier PJ. Bone mineral density of the hip measured with dual-energy X-ray absorptiometry in normal elderly women and in patients with hip fracture. Osteoporos Int 1991;1(4):242-9. Crossref

14. Heikinheimo RJ, Inkovaara JA, Harju EJ, Haavisto MV, Kaarela RH, Kataja JM, Kokko AML, Kolho LA, Rajala SA. Annual injection of vitamin $D$ and fractures of aged bones. CalcifTissue Int 1992;51(2):105-10. Crossref

15. Byberg L, Bellavia A, Orsini N, Wolk A, Michaëlsson K. Fruit and vegetable intake and risk of hip fracture: a cohort study of Swedish men and women. J Bone Miner Res 2015;30(6):97684. Crossref

16. Fung $\mathrm{T}$, Arasaratnam $\mathrm{MH}$, Grodstein $\mathrm{F}$, Katz JN, Rosner B, Willett WC, Feskanich D. Soda consumption and risk of hip fractures in postmenopausal women in the Nurses' Health Study. Am J Clin Nutr 2014;100(3):953-8. Crossref

17. Holbrook TL, Barrett-Connor E, Wingard DL. Dietary calcium and risk of hip fracture: 14-year prospective population study. Lancet 1988;332(8619):1046-9. Crossref

18. Cummings SR, Nevitt MC; Osteoporotic Fractures Research Group. Non-skeletal determinants of fracture: the potential importance of the mechanics of falls. Osteoporosis Int 1994;4(S1):S67-70. Crossref

19. Province MA, Hadley EC, Hornbrook MC, Lipsitz LA, Miller JP, Mulrow CD, Ory MG, Sattin RW, Tinetti ME, Wolf SL. The effects of exercise on falls in elderly patients. A preplanned meta-analysis of the FICSIT Trials. Frailty and Injuries: Cooperative Studies of Intervention Techniques. JAMA 1995;273(17):1341-7. https://pubmed.ncbi.nlm.nih. gov/7715058/ 
20. Schwartz AV, Kelsey JL, Sidney S, Grisso JA. Characteristics of falls and risk of hip fracture in elderly men. Osteoporos Int 1998;8(3):240-6. Crossref

21. Grisso JA, Kelsey JL, Strom BL, Chiu GY, Maislin G, O'Brien LA, Hoffman S, Kaplan F. Risk factors for falls as a cause of hip fracture in women. The Northeast Hip Fracture Study Group. N Engl J Med 1991;324(19):1326-31. Crossref

22. Yang $Y$, Mackey DC, Liu-Ambrose $T$, Feldman F, Robinovitch SN. Risk factors for hip impact during real-life falls captured on video in long-term care. Osteoporos Int 2016;27(2):53747. Crossref

23. Visschedijk J, Achterberg W, Van Balen R, Hertogh C. Fear of falling after hip fracture: A systematic review of measurement instruments, prevalence, interventions, and related factors. J Am Geriatr Soc 2010;58(9):1739-48. Crossref
24. Papaioannou A, Santesso N, Morin SN, Feldman S, Adachi JD, Crilly R, Giangregorio LM, Jaglal S, Josse RG, Kaasalainen S, Katz P, Moser A, Pickard L, Weiler H, Whiting S, Skidmore CJ, Cheung AM; Scientific Advisory Council of Osteoporosis Canada. Recommendations for preventing fracture in longterm care. CMAJ 2015;187(15):1135-44. Crossref

25. Tinetti ME, Baker DI, McAvay G, Claus EB, Garrett P, Gottschalk M, Koch ML, Trainor K, Horwitz RI. A multifactorial intervention to reduce the risk of falling among elderly people living in the community. N Engl J Med 1994;331(13):821-7. Crossref

26. Neuman MD, Silber JH, Magaziner JS, Passarella MA, Mehta $S$, Werner RM. Survival and functional outcomes after hip fracture among nursing home residents. JAMA Intern Med 2014;174(8):1273-80. Crossref 